\title{
Evaluation of the quality of life in subjects with a history of severe anaphylactic reaction to the Hymenoptera venom
}

The authors declare no financial disclosure

\begin{abstract}
Introduction: Sensitization to the Hymenoptera venom is one of the main causes of anaphylaxis in Poland. Venom immunotherapy is the only effective treatment in such cases. Comprehensive patient care includes also education. The aim of our study was to assess the state of knowledge and to evaluate the quality of life and the anxiety level in patients allergic to the Hymenoptera venom after anaphylactic reaction.

Material and methods: The survey was carried out in the period of the insects flight in 61 adult subjects (35 wasp and 26 bee allergic), using a validated Vespid Allergy Quality of Life Questionnaire (VOLO), Hospital Anxiety and Depression Scale, and subjective assessment of anxiety level. The majority of respondents received venom immunotherapy.

Results: Sensitized to the wasp venom had significantly impaired quality of life (VOLO score) as compared to the bee venom allergic $(p=0.014)$. The intensity of anxiety decreased with the duration of immunotherapy $(p=0.01)$. The majority of subjects knew how to recognize and treat anaphylaxis, but only $8 \%$ employed an identification card and about $50 \%$ implemented rules of the pre-exposition prophylaxis.

Conclusions: History of a severe anaphylaxis to the Hymenoptera venom affected the quality of life. Venom immunotherapy reduced anxiety. We hope that presented surveys and their results might be useful in qualifying for immunotherapy in clinically uncertain cases.
\end{abstract}

Key words: anaphylaxis, Hymenoptera, venom immunotherapy, quality of life, VQLO

Pneumonol Alergol Pol 2015; 83: 352-358

\section{Introduction}

Ever since thinkers such as Hippocrates and Aristotle, thought was given to the foundation of happy and fulfilling life [1]. In modern decades, this issue again began to play an important role [2]. The concept of Health Related Quality of Life (HRQL) includes the following areas of life: physical condition, mental and spiritual states, social and economic conditions, and somatic sensations [2]. Until recently, in allergology, the quality of life was assessed only in patients with asthma, allergic rhinitis and conjunctivitis, by examining the impact of disruptive clinical symptoms on the patient's well-being. Although people allergic to the Hymenoptera venom have no signs of allergic disease, when not exposed to stings, however lack of symptoms does not mean the absence of impact on their lives. Here, the quality of life is influenced mainly by continuous anxiety and vigilance against repetitive stings and uncertainty of what will happen in the event of unexpected allergen exposure, including risk of brain damage, heart attack, or even sudden death [3, 4]. Fortunately, the risk of death after Hymenoptera stings is not high, estimated at $0.09-0.45 / 1$ million 
inhabitants/year [5]. For most people allergic reaction to the Hymenoptera venom is a very traumatic experience [4]. During insect flight seasons these persons limit daily activities, give up their hobby, avoid certain places, such as grocery stores or bars, and reduce spending time outdoors. Despite being equipped with a set of "rescue" medications, including an epinephrine injection kit, patients report that they experienced anxiety and even terror, when stinging insect appeared in the environment.

A group of researchers from the Netherlands and Canada recently developed an innovative questionnaire for persons allergic to wasp venom: the Vespid Allergy Quality of Life Questionnaire (VQLQ) [6, 7]. The Polish version of this questionnaire was developed by a team from the Medical University of Gdansk [8]. The Clinic of Allergy and Immunology in Krakow is one of the few centres in Poland that carry out accurate diagnosis of allergy in adults with a history of systemic reactions to stings, and subsequently apply specific venom immunotherapy (VIT), which is the only proven therapeutic method [5]. It should be applied in cases with a history of severe IgE-mediated anaphylactic reactions. Sometimes this treatment can be also considered after reactions to stings, which occurred as a generalized urticaria [9], or even (as recommended by the American Academy of Asthma, Allergy and Immunology) as recurrent large local reactions, as long as this condition significantly hinders the patient's life, especially with high-risk of repeated exposure to venom (eg. with relation to their professional activity), accompanied by the serious fear of repetitive stings [10]. Since the assessment of the life quality makes it possible to detect the person's specific problems, and hence allows for an individual approach to the patient and for providing him with appropriate assistance, a survey among patients with a history of anaphylactic reaction to the Hymenoptera venom, has been performed.

\section{Material and methods}

\section{Patients}

The study was conducted between May and October 2013, the flight season of Hymenoptera. All consecutive patients with a history of anaphylactic reaction after Hymenoptera stings were invited to complete the survey. In total, the study involved 61 adults: 35 with wasp venom and 26 with bee venom allergy.

\section{Description of the survey}

Each patient included in the study answered the questionnaire evaluating the quality of life, only once. The questionnaire consisted of two parts. The first part was filled by the patient with the help of the doctor or nurse. It had the form of a detailed allergology history. The second part of the questionnaire, which consisted of the Polish version of VQLQ and the Hospital Anxiety and Depression Scale (HADS) was completed by the patients independently. In addition, the survey included an analogue scale from " 0 " to "100", which aimed to determine to determine the intensity of a current fear of the stings. There were also questions about some aspects of daily life, relationships with family, neighbours and friends, reflections on changing in work because of the sensitization and a request for an answer about, what the disease has changed the most in the patient's life.

We received the original Polish version of the VQLQ questionnaire by the courtesy of Professor Marek Niedoszytko. The questionnaire contained 14 questions. The first six questions referred to the symptoms of anxiety and the concerns related to the avoiding of stinging insects; the next eight questions examined the level of patients' alertness during normal and specific life activities [6]. To each question 7 possible answers, reflecting the potential impact of allergy on patient life, have been prepared. The patient had to answer each question assigning scores from 1 (severe deterioration) to 7 (no deterioration) [9]. Then the total number of points was counted and divided by the number of questions that is by 14 . The final result of the arithmetic mean was interpreted as the result of the VQLQ questionnaire.

The HAD scale, was constructed by Zigmond and Snaith [9] and adapted for patients suffering from various somatic diseases. Its purpose is to assess the negative emotions in form of anxiety and depression in a population of patients with no psychiatric disorders. [9]. The scale in its original version consists of 7 items testing anxiety and, 7 items relating to depressive states. The individual interpretation of this scale includes the following categories: $0-7$ points - no disturbance; $8-10$ points - borderline states; $11-21$ points - disturbances $[11,12]$. The Polish version of this research tool has also been made available to us by Professor Niedoszytko.

On the analogue scale from " 0 " to " 100 " - " 0 " meant complete lack of fear or anxiety, and " 100 " - maximum fear and anxiety of further stings. 
Table 1. Demographic characteristics of the respondents

\begin{tabular}{|c|c|c|c|}
\hline & $\begin{array}{l}\text { Allergic to wasp venom, } \\
\qquad \mathrm{n}=35\end{array}$ & $\begin{array}{l}\text { Allergic to bee venom, } \\
n=26\end{array}$ & $\mathbf{p}$ \\
\hline $\begin{array}{l}\text { Age: } \\
\text { median, (interquartile range) }\end{array}$ & $43(36-54)$ & $47(39-61)$ & NS \\
\hline Gender: (women/men) & $16 / 19$ & $14 / 12$ & NS \\
\hline $\begin{array}{l}\text { Place of residence: urban/rural } \\
\mathrm{n}(\%)\end{array}$ & $19(54 \%) / 16(46 \%)$ & $7(27 \%) / 19(73 \%)$ & 0.03 \\
\hline $\begin{array}{l}\text { Education: } \\
\mathrm{n}(\%)\end{array}$ & $\begin{array}{c}\text { primary: } 3(8,6 \%) \\
\text { vocational: } 12(34 \%) \\
\text { secondary: } 9(26 \%) \\
\text { higher: } 11(31,4 \%)\end{array}$ & $\begin{array}{c}\text { primary: } 1(4 \%) \\
\text { vocational: } 4(15 \%) \\
\text { secondary: } 10(38,5 \%) \\
\text { higher: } 11(42,5 \%)\end{array}$ & \\
\hline $\begin{array}{l}\text { Occupation: } \\
\mathrm{n}(\%)\end{array}$ & $\begin{array}{c}\text { unemployed: } 10(28,6 \%) \\
\text { office workers: } 10(28,6 \%) \\
\text { physical workers (outdoors activities): } \\
13(37,1 \%) \\
\text { bee-keepers: } 0 \\
\text { farmers: } 2(5,7 \%)\end{array}$ & $\begin{array}{c}\text { unemployed: } 10(38,5 \%) \\
\text { office workers: } 9(34,6 \%) \\
\text { physical workers (outdoors activities): } \\
5(19,2 \%) \\
\text { bee-keepers: } 1(3,8 \%) \\
\text { farmers: } 1(3,8 \%)\end{array}$ & \\
\hline $\begin{array}{l}\text { Leisure activities: } \\
\mathrm{n}(\%)\end{array}$ & $\begin{array}{c}\text { outdoors only: } 8(22,8 \%) \\
\text { indoors only: } 12(34,3 \%) \\
\text { indoors and outdoors: } 15(42.8 \%)\end{array}$ & $\begin{array}{c}\text { outdoors only: } 12(46,1 \%) \\
\text { indoors only: } 5(19,2 \%) \\
\text { indoors and outdoors: } 9(34,6 \%)\end{array}$ & \\
\hline
\end{tabular}

NS - non-significant

In addition, patients were questioned in details about their health education state regarding anaphylaxis and their compliance with specific safety rules in everyday life, in order to avoid unwanted exposure to the venom. This element of the study was not only of cognitive value, but first of all increased the respondents' current knowledge.

The survey was begun having obtained a positive opinion of the Jagiellonian University Bioethics Committee.

\section{Statistical analysis}

The StatSoft STATISTICA 10.0 software was used for statistical calculations. The normality of numerical data distribution was defined with the use of the Shapiro-Wilk test. The distribution occurred to be non-normal; therefore Tables showed the median and the interquartile range. Differences between the individual groups of subjects were calculated with the use of the U-Mann-Whitney test. Distribution of demographic data and compliance with the rules prior to exposure to Hymenoptera venom was compared using the chi-square test. The linear regression model was employed to assess the effect of co-morbidities, complications during VIT, duration of VIT, and patients' education on the intensity of anxiety and VQLQ score, as well as effect of education level on the compliance with relevant rules of pre-exposition prevention.
The level of $p<0.05$, was assumed to be statistically significant.

\section{Results}

Table 1 shows demographic data of respondents according to the allergy type. Groups did not differ with regard to age and gender. People allergic to the wasp venom lived both in rural and urban areas, while those with an allergy to bee venom lived mainly in rural areas $(p=0.03)$. With the exception of 2 patients all respondents were already in the course of immunotherapy, of which $56 \%$ have been treated for more than two years, $15 \%$ from $0.5-1$ year, $10 \% 1-2$ years, and 19\% have been desensitized for less than 6 months (with no difference between wasp and bee allergy). More than half of the patients had no other co-morbidities, while the remaining were treated due to a concomitant disease: hypertension (23\%), allergic rhinitis (13\%) and asthma (6\%). Family history of allergy to Hymenoptera venom in $82 \%$ of patients was negative.

\section{The VQLQ questionnaire and the anxiety level (scale " 0 " to " 100 ")}

Table 2 shows the results of the VQLQ survey and the anxiety level measured on a scale from "0" to "100". In allergic to the wasp venom the VQLQ survey showed lower scores (poorer quality of life), than in bee allergic $(p=0.014)$. Such a relationship was not found for the anxiety 
Table 2. VQLO score and anxiety level measured in the scale from " 0 " to "100". The table shows the median and interquartile range

\begin{tabular}{lcccccc}
\hline & $\begin{array}{c}\text { Women } \\
\mathbf{n = 3 0}\end{array}$ & $\begin{array}{c}\text { Men } \\
\mathbf{n = 3 1}\end{array}$ & $\mathbf{p}$ & $\begin{array}{c}\text { Allergic to wasp venom, } \\
\mathbf{n = 3 5}\end{array}$ & $\begin{array}{c}\text { Allergic to bee venom, } \\
\mathbf{n}=\mathbf{2 6}\end{array}$ & $\mathbf{p}$ \\
\hline VQLO & 4.57 & 5.29 & NS & 4.45 & 5.29 & $(4.71-6.17)$ \\
Anxiety & $(3.42-5.29)$ & $(3.92-6.15)$ & & $(3.22-5.75)$ & 15.0 & NS \\
& 34.5 & 15.0 & NS & 20.0 & $(5-39.5)$ &
\end{tabular}

level. It has been shown that the vast majority of patients allergic to the wasp venom, "every day in the summer would think about their allergy" and were "horrified at the possibility of further stings." In the group of patients allergic to bee venom there was $2.5 \times$ less of such people $(p=0.0004$ and $p=0.02$, respectively). Half of the patients who were allergic to wasp venom admitted they "refrained from outdoor professional activities", while there was twice less such persons in the bee venom allergic group (difference statistically non significant). A similar trend was observed in terms of planning holiday trips: slightly more of those allergic to wasp choose places free from stinging insects, and with easily accessible medical facilities. In both groups, the majority of respondents would avoid direct sunlight, limit walking, cycling and practicing their favourite sport, for fear of possible stings.

The linear regression model showed that the severity of an anaphylactic reaction to stings in the past, complications of venom immunotherapy, occasional stings occurring during VIT (27\% declared such), co-morbidities, as well as the subjectively assessed by respondents themselves, knowledge on anaphylaxis, and the fact of being equipped with an emergency anaphylaxis kit, did not affect the patients' level of anxiety on a scale from " 0 " to " 100 ", or the VQLQ result. The only factor affecting the severity of anxiety was the length of immunotherapy $\left(p=0.01, R^{2}\right.$ $=0.09$ ), the longer the duration of VIT, the lower anxiety level. For the VQLQ only such trend was demonstrated $(p=0.09)$. On the other hand, local skin reactions after vaccine administration were important for the VQLQ ( $\left.p=0.01, \mathrm{R}^{2}=0.09\right)$, reported as significantly higher negatively affected the VQLQ score.

\section{The HAD scale}

Among respondents in both groups the vast majority ( $76 \%$ and $75 \%$ ) did not demonstrate any anxiety. $12 \%$ of patients allergic to wasp venom and $12.5 \%$ to bee venom demonstrated borderline disorders and almost the same amount had significant disorders. According to the depression rating scale, respectively $94 \%$ and $91 \%$ of patients were within normal values. Border result indicating mild depression, was demonstrated in $6 \%$ (allergic to wasp venom) and 9\% (allergic to bee venom) of patients. None of the respondents demonstrated significant disturbances. Between patients allergic to the wasp and bee venom both in the assessment of anxiety and in the assessment of depression, no statistically significant differences have been found on this scale.

\section{Knowledge about anaphylaxis and adherence to the principles of pre-exposition prevention}

$89 \%$ of respondents admitted to have at least once received accurate information on the symptoms, course and treatment of anaphylactic reaction to stings, of which only $76 \%$ indicated that this information helped them reduce fear and anxiety (with no difference between wasp and bee venom allergy). 51 respondents (83\%) stated they carried an epinephrine emergency anaphylaxis kit and would use it if necessary (also no difference between the two groups). On the other hand, only 5 patients (8\%) carried some information if they were allergic (bracelet/card with a diagnosis). $75 \%$ of respondents (the same in both groups) would be able to recognize the symptoms of an incipient systemic reaction. The most important factor with an impact on anaphylaxis knowledge degree, was the respondents' level of education (lineal regression model, $\mathrm{p}=0.005, \mathrm{R}^{2}=0.11$ ). On the other hand, education did not affect either the VQLQ score, or the level of anxiety assessed on a scale " 0 " to " 100 ", nor did it affect compliance with relevant rules of pre-exposition prevention. A particularly interesting result was obtained in this part of the survey which analyzed insect venom allergy, in terms of family relationships and the environment. Almost 90\% reported that their 
Table 3. Compliance with the safety behavior rules by patients, allergic to the wasp and bee venom during flight season of insects. The number and percentage of subjects adhering to the given principle in everyday life was shown in the table

\begin{tabular}{|c|c|c|c|c|}
\hline & Safety rule & $\begin{array}{l}\text { Allergic to wasp } \\
\text { venom; } \\
\text { n (\%) }\end{array}$ & $\begin{array}{l}\text { Allergic to bee } \\
\text { venom; } \\
\text { n (\%) }\end{array}$ & $\mathbf{p}$ \\
\hline 1. & I do not keep food in the open air & $21(60)$ & $11(42)$ & NS \\
\hline 2. & I avoid walking barefoot outdoors & $16(46)$ & $10(38)$ & NS \\
\hline 3. & I avoid accumulation of garbage close to the house & $13(37)$ & $12(46)$ & NS \\
\hline 4. & I eat fewer meals out in restaurants (bars, restaurants) & $12(34)$ & $1(4)$ & 0.004 \\
\hline 5. & I eat fewer meals outdoors & $12(34)$ & $2(8)$ & 0.01 \\
\hline 6. & I limit errands in open retail sites & $11(31)$ & $1(4)$ & 0.007 \\
\hline 7. & I mount the net on the windows to prevent insects getting into the apartment & $9(26)$ & $2(8)$ & NS \\
\hline 8. & I do not use fragrances in the apartment & $7(20)$ & $1(4)$ & NS \\
\hline 9. & I pay attention to the colour of the clothes, avoiding intense and pastel colours & $7(20)$ & $4(16)$ & NS \\
\hline 10. & I try not to take out waste in the trash, another member of the family does it & $6(17)$ & $2(8)$ & NS \\
\hline 11. & I do not keep fresh flowers in the house & $6(17)$ & $0(0)$ & 0.03 \\
\hline 12. & I consume less alcohol in the house or outside & $4(11)$ & $1(4)$ & NS \\
\hline 13. & I do not go barefoot around the house & $6(17)$ & $4(16)$ & NS \\
\hline 14. & I use less cosmetics fragrances & $6(17)$ & $3(12)$ & NS \\
\hline 15. & I avoid using public toilets & $5(14)$ & $1(4)$ & NS \\
\hline 16. & I choose complete clothes (long sleeve, long trousers, hat) & $4(11)$ & $3(12)$ & NS \\
\hline 17. & I avoid opening windows and doors & $4(11)$ & $0(0)$ & NS \\
\hline 18. & I use adhesive tape to attach insects & $3(9)$ & $3(12)$ & NS \\
\hline 19. & I do not hang laundry outside & $1(3)$ & $0(0)$ & NS \\
\hline 20. & I do not use scented laundry liquids & $1(3)$ & $0(0)$ & NS \\
\hline 21. & I choose shoes that cover the entire foot & $1(3)$ & $3(12)$ & NS \\
\hline
\end{tabular}

closest family feared the next reactions to stings. The same number of patients claimed discussing their allergy with friends, but only $10 \%$ discussed the procedures in case of anaphylactic reaction with their family members and friends. In relations with neighbours, this percentage was even lower (6\%). Also here, no statistical differences between the two groups were found.

Table 3 shows the results concerning compliance with rules intended to avoid unwanted exposure to the venom. What draws attention is poor compliance in both groups.

To the question: "What has the disease changed the most in your life", patients allergic to wasp venom placed as first, the need to comply with safety rules in order to avoid further stings, and as the second they mentioned reduction of the joy of life and withdrawal from life, and as the third - fear. Patients allergic to bee venom also mentioned as first, compliance with safety rules, the second was fear, but on the third place there was the need of change of professional activity or hobby (with a statistically significant difference compared to patients allergic to wasp venom).

\section{Discussion}

Hypersensitivity to Hymenoptera venom with a history of severe anaphylactic reaction adversely influenced the quality of further life. In our study, this observation referred more to wasp allergy, what is probably associated with the biological behaviour and wide spread of these insects in both rural and urban areas. It is also important that the intensity of fear of further stings decreased along with the duration of venom immunotherapy. Therefore, appropriate treatment (VIT), not only protected patients from the potential risk of anaphylaxis and death after the stings, but also significantly reduced the anxiety level. This is another argument for an urgent qualification and immediate implementation of 
desensitisation therapy for all those, who meet the eligibility criteria for VIT. On the other hand, in patients with confirmed IgE-mediated allergy to insect venom and an uncertain clinical history (eg. isolated urticaria or unclear anaphylaxis course) documented assessment of life quality and of subjective fear, can be an important element of verification when considering comprehensive indications for VIT. It has not been shown so far, that carrying epinephrine reduces anxiety and improves the quality of life in these patients [14]. Moreover, in patients with a particularly severe sense of threat implementing intensive educational activities, recommending following pre-exposition prevention rules, and in some cases providing support from a clinical psychologist, would be advisable. We hope that the results of our survey, especially those demonstrating anxiety intensity, and the VQLQ scores, will be useful for sites wishing to implement this element of comprehensive patient care in cases of allergy to insect venom. So far, only several such studies have been conducted both in Poland and in the world [7, 8, 13]. The quality of life of our respondents as assessed with the VQLQ questionnaire seems to be better than in an analysis carried out by a team from Gdansk, in patients before the start of VIT, but very similar to the results obtained in patients after one year of desensitization therapy [8]. Similar VQLQ scores have been obtained by a Dutch team in patients prior to desensitization treatment who demonstrated only cutaneous reactions to the wasp venom [9].

Family history of allergy to insect stings in a great majority of our patients was negative. Multiple stings have not been shown to be a risk factor for a more severe anaphylactic reaction (data not presented). These findings remain in line with the contemporary state of knowledge [15]. As shown in the results section, better educated persons, scored higher, as regards knowledge about anaphylaxis, but this did not affect their quality of life, severity of anxiety, or better compliance with pre-exposition prevention principles. On the other hand, however, despite oral and written recommendations, as much as $20 \%$ of respondents did not carry the emergency epinephrine anaphylaxis kit during insect flight season, and only 5 of the 61 patients carried information about their allergies. It is also important that the majority of respondents did not comply with the fundamental principles of pre-exposition prevention rules and some rules were not applied at all by any of the respondents (Table 3). This reflects the lack of knowledge and indicates the need for further education (especially of the less educated) while visiting the allergist office. Comprehensive care for patients with allergy to insect stings must therefore take into account not only the specific immunotherapy, but also include efforts to increase knowledge of both the patient and relatives of the patient's environment (family, friends). Very few of our respondents discussed the principles of proper behaviour in the case of an anaphylactic reaction to stings with their friends or colleagues. The study respondents admitted that they "did not want to scare" their relatives by their allergy and also pointed to the fear of social stigma. However, it cannot be excluded that people from the close environment who in the event of severe anaphylactic reaction would adopt emergency anaphylaxis procedures.

Our study points to the need of drawing special attention to people who are allergic to insect stings to changing their daily routine during insect flight seasons in terms of pre-exposition prevention. The most important of these recommendations are presented in Table 3. It appears that such guidance should also be communicated to a wider social group, including those non-allergic, as healthy behaviours, aiming at avoiding of unwanted exposure with the risk of insect venom allergy development. Support from the media e.g. series of short TV programs or websites presenting issues of pre-exposition prevention with regard to natural behaviour of stinging insects, would be of help. The dynamic growth in the number of anaphylactic reactions in the last decade, where wasp, bee, hornet or bumblebee stings account for about $50 \%$ of these complications, should lead to taking measures for health promotion with this regard.

\section{Limitation of the study}

Presented study has also several limitations. First of all, the number of subjects is low. In a situation, when only a few responders gave a positive answer to the questions raised, the epidemiological inference is obviously impossible. Besides that, recruited patients were at the different stage of VIT, what caused that the group was heterogeneous. Nevertheless, we believe that the given below conclusions are truthful.

\section{Conclusions}

The history of an anaphylactic reaction in people allergic to the insect venom negatively affects the quality of life. Immunotherapy significantly reduces the severity of anxiety in these 
cases. It seems that the proposed surveys may be useful when qualifying patients for immunotherapy in clinically uncertain cases.

\section{Conflict of interest}

The authors declare no conflict of interest.

\section{References:}

1. Trzebiatowski J. Jakość życia w perspektywie nauk społecznych i medycznych - systematyzacja ujęć definicyjnych. Hygeia Public Heath 2011; 46: 25-31.

2. Kochman D. Jakość życia. Analiza teoretyczna. Zdr Publ 2007; 117: $242-248$

3. Joanne NG, Oude Elberink JN. Significance and rationale of studies of health-related quality of life in anaphylactic disorders. Curr Opin Allergy Clin Immunol 2006; 6: 298-302.

4. Rozpoznanie, profilaktyka i leczenie alergii na jad owadów błonkoskrzydłych. Wytyczne European Academy of Allergology and Clinical Immunology. Wyd. Medycyna Praktyczna. Wydanie specjalne 3/2006.

5. Nittner-Marszalska M. Alergia na owady błonkoskrzydłe. In Fal AM. (ed.). Alergia, choroby alergiczne, astma. T. II. Kraków 2011: $465-479$.

6. Fischer J., Feidt A., Giel K.E. et al. Quality-of-life in wasp venom allergy - validation of the German version of the „Vespid Allergy Qualityof Life Questionnaire”(VQLQ-d). J Dtsch Dermatol Ges. 2011; 9: 379-85. doi: 10.1111/j.1610-0387.2011.07622.x.
7. Oude Elberink JN, De Monchy JG, Golden DB, Brouwer JL, Guatt GH, Dubois AE. Development and validation of a health-related quality-of-life questionnaire in patients with yellow jacket allergy. J Allergy Clin Immunol 2002; 109: $162-170$.

8. Niedoszytko M., Majkowicz M., Chełmińska M., Buss T., Gruchała-Niedoszytko M., Jassem E. Quality of life, anxiety, depression and satisfaction with life in patients treated with insect venom immunotherapy. Post Dermatol Alergol 2012; XXIX, 2: 74-79.

9. Oude Elberink JN, van der Heine S., Guyatt GH, Dubois AE: Immunotherapy improves heath-related quality of life of adult patients with dermal reactions following yellow jacket stings. Clin Exp Allergy 2009; 39: 883-889. doi: 10.1111/j. 1365-2222.2009.03230.x

10. Cox L., Nelson H, Lockey R et al. Allergen immunotherapy: A practice parameter third update. J Allergy Clin Immunol 2011; 127: S1-S55. doi: 10.1016/j.jaci.2010.09.034.

11. Zigmond AS, Snaith RP. The Hospital Anxiety And Depression Scale. Acta Psychiatr Scand 1983; 67: 361-370.

12. De Walden-Gałuszko K., Majkowicz M. Jakość życia w chorobie nowotworowej. Gdańsk 1994.

13. Cichocka-Jarosz E, Brzyski P, Tobiasz-Adamczyk B, Lis G, Pietrzyk JJ. Development of children's hymenoptera venom allergy quality of life scale (CHVAQoLS). Clin Transl Allergy 2013; 3: 25. doi: 10.1186/2045-7022-3-25.

14. Rueff F, Bilo BM, Cichocka-Jarosz E. Immunotherapy for hymenoptera venom allergy: too expensive for European health care? Allergy 2013; 68: 407-8

15. Nittner-Marszalska M. Alergia na owady. In: Pawliczak R. (ed.) Alergologia — kompendium. Poznań 2013: 213-217. 